\title{
Utility of Peripheral Blood Parameters in Predicting Breast Cancer Risk
}

\author{
Yildiz Okuturlar ${ }^{1 *}$, Meral Gunaldi², Elif Eda Tiken ${ }^{3}$, Bugra Oztosun', Yesim \\ Ozdem Inan $^{2}$, Tarik Ercan ${ }^{1}$, Savas Tuna ${ }^{2}$, Ali Osman Kaya², Ozlem Harmankaya ${ }^{1}$, \\ Abdulbaki Kumbasar ${ }^{1}$
}

\begin{abstract}
Purpose: We aimed to study the inflammatory parameters of complete blood count in breast cancer cases. Materials and Methods: This retrospective study covered 178 breast cancer patients and 107 age and body mass index matched healthy women. Complete blood count parameters, neutrophil/lymphocyte ratio (NLR), platelet/ lymphocyte ratio (PLR) and MPV/platelet were analyzed. Results: The leukocyte, neutrophil and neutrophil/ lymphocyte ratio were higher in the patient group (p values $0.001,0.0001$ and 0.0001 , respectively) while haemoglobin and hematocrit were higher in the control group $(\mathrm{p}=0.0001$ for both). Logistic regression analysis showed that elevated neutrophils and platelet distribution width (PDW) (OR: 0.627,95\% CI: 0.508-0.774, p=0.001 and OR: $1.19195 \% \mathrm{CI}: 1.057-1.342 \mathrm{p}=0.003$ ) were independent variables for predicting breast cancer. The cutoff value for the neutrophil/lymphocyte ratio was 2.56. Conclusions: According to our study results, neutrophil levels as part of complete blood count may be used as an independent predictor of breast cancer risk.
\end{abstract}

Keywords: Breast cancer - complete blood count - neutrophils - platelet distribution width

Asian Pac J Cancer Prev, 16 (6), 2409-2412

\section{Introduction}

The most common malignancy among women is breast cancer (Islam et al., 2014). It was estimated by The American Cancer Society (ACS) that $29 \%$ of all new malignant diseases are breast cancer and it is $16 \%$ cause of deaths (Siegel et al., 2012). Personal and family history of breast cancer, age, overweight, menstrual history, genetics, radiation to chest or face before age 30 , pregnancy/breast feeding, race/ethnicity, hormone replacement therapy, alcohol consumption, dense breast, lack of exercise and smoking are the most important determinant factors of breast cancer (Majeed et al., 2014). Inflammation seems to be a shared process in the all risk factors of cancer identified till now. Activated inflammatory process is considered to be involved in invasion, tumor growth, metastasis and angiogenesis (Aggarwal and Gehlot, 2009; Pierce et al., 2009). Therefore, several inflammatory markers in the blood count such as platelets, neutrophils, lymphocytes, neutrophil/lymphocyte ratio (NLR), platelet/ lymphocyte ratio (PLR), mean platelet volume (MPV) have been studied in different patients with malignant tumors (Teramukai et al., 2009; Gasparyan et al., 2011; Unal et al., 2013). As far as we know, there is only one study that compare some blood parameters (leukocyte, haemoglobin, platelet) between the breast cancer patients and healthy controls (Ufelle et al., 2012). But it does not contain other complete blood count parameters as PLR, MPV, NLR, etc. So in this retrospective study we aimed to compare all complete blood count indices between breast cancer patients and healty controls.

\section{Materials and Methods}

This study was approved by our hospital local ethical committee. Our hospital's records between January 2011 and June 2014 were reviewed and with International Classification of Diseases (ICD) code (C50) of patients of breast cancer were determined and their post-surgery retrospective data were analyzed. In this study, a total of 320 records were scanned and 142 patients of those were excluded because of the presence at least one of the following criteria: Diagnostic mismatch between the ICD code and the histopathological results, absence of the pre-chemotherapy complet blood count results, absence of the investigations necessary for staging of the cancer such as thoracic and abdomino pelvic computed tomography (CT), magnetic resonance imaging (MRI) and positron emussion tomography (PET).

Age, weight, height, menopausal status, histopathological reports, mammography, breast MRI, thoracic and abdomino pelvic CT, PET reports, complete 
Yildiz, Okuturlar et al

blood count parameters, NLR, PLR and MPV/platelet values results of the remained 178 patients were analyzed. Disease staging was performed according to the tumornode-metastasis (TNM) staging system of the American Joint Committee on Cancer (AJCC) (Edge and Compton, 2010). The control group consisted of 107 age and body mass index (BMI) matched healthy women. Complete blood count was determined by a Coulter LH 750 auto analyser (Beckman Coulter, CA, USA).

\section{Statistical analysis}

Statistical analyses were performed using SPSS 22.0 statistical package for Windows. Continuous data were expressed as mean standard deviation, while categorical data were presented as number of patients. The distribution of variables was checked with the kolmogorov-smirnov test. Chi-square test was used for comparison of categorical variables, while student-t test was used to compare continuous variables. Logistic regression analysis was performed to determine the independent predictors of breast cancer. Receiver operating characteristic (ROC) curve analysis was performed to determine the cut-off level of leukocyte, neuthrophil, NLR to predict the dipper versus non-dipper status. $\mathrm{p}$ values less than 0.05 were considered statistically significant.

\section{Results}

The records of 178 women with breast cancer and 107 healthy control women were analysed. There was no statistically significant difference in mean age between patient and control groups $(53.8 \pm 11.47$ vs $53.72 \pm 14.69$ years, respectively, $\mathrm{p}=0.96$ ). The staging of breast cancer patients was as follow: Stage 1 (13.4\%), stage II (40.9\%), stage III $(36.6 \%)$ and stage IV $(9.1 \%)$. Characteristics of the two groups are shown in Table 1.

The rate of NLR was significantly higher in breast cancer patients than in the control group $(2.37 \pm 1.4 \mathrm{vs}$ $2 \pm 1.26$, respectively, $\mathrm{p}=0.0001$ ). The mean haemoglobin $(\mathrm{Hb})$ and haematocrit $(\mathrm{Hct})$ levels in the patient group were significantly lower than the control group $(12.21 \pm 1,38 \mathrm{~g} /$ $\mathrm{dl}$ and $37.36 \% \pm 3.84 \mathrm{vs} 13.24 \pm 0.88 \mathrm{~g} / \mathrm{dl}$ and $40.20 \% \pm 2.58$, respectively, $\mathrm{p}=0.0001 \mathrm{in}$ both). There were no significant differences in PLR and MPV/platelet values between two groups ( $>0.05)$ (Table 2).

A neutrophil count more than $2.56 \times 10^{4} / \mathrm{mm}^{3}$ had a sensitivity of $59 \%$, a specificity of $70.8 \%$, a positive predictive value of $77.2 \%$, and a negative predictive value of $50.7 \%$ in predicting breast cancer [(area under curve was $0.675(0.611-0.740)$ and $\mathrm{p}=0.0001]$. The cutoff values of leukocyte, neutrophil and NLR (Figure 1) levels for predicting breast cancer were determined by ROC analysis (Table 3).

The subanalysis of the patients group, platelet levels as well PLR values were higher in premenopausal subgroup than postmenopausal sub-group $(298.76 \pm 71.32$ and $169.1 \pm 87.25$ vs $276.06 \pm 70.94$ and $141.16 \pm 64.61$, $\mathrm{p}$ was 0.037 and 0.002 , respectively). The difference in the leukocyte, neutrophils, lymphocytes, $\mathrm{Hb}$, Hct, mean corpuscular volume (MCV), MPV, MPV/PLT ratio, platelet distribution width (PDW), NLR values

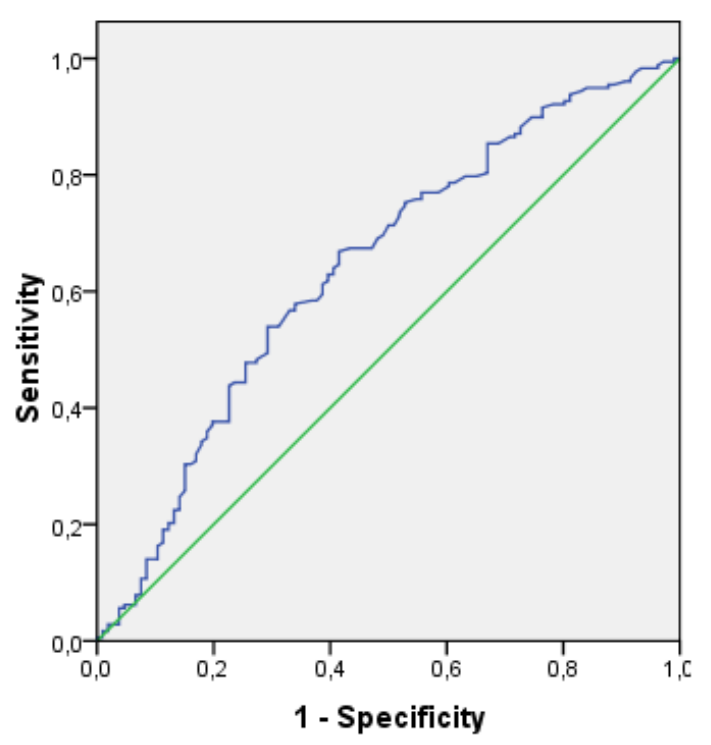

Figure 1. ROC analysis for NLR to Predict Breast Cancer (Area Under Curve 0.642)

Table 1. Characteristics of the Patient and Control Groups

\begin{tabular}{lrrl}
\hline Parameter & $\begin{array}{c}\text { Patients } \\
\mathrm{n}=178\end{array}$ & $\begin{array}{c}\text { Controls } \\
\mathrm{n}=107\end{array}$ & $\mathrm{p}$ value \\
\hline Age (years) & $53.8 \pm 11.5$ & $53.7 \pm 14.7$ & 0.96 \\
BMI $\left(\mathrm{kg} / \mathrm{m}^{2}\right)$ & $28.8 \pm 5.37$ & $29.9 \pm 4.72$ & 0.076 \\
Stage I & $22(13.4)$ & & \\
II & $67(40.9)$ & & \\
III & $60(36.6)$ & & \\
IV & $15(9.1)$ & & \\
Menopausal Status & & & \\
$\quad$ Premenopausal & $78(43.8)$ & & \\
$\quad$ Postmenopausal & $100(56.2)$ & & \\
Tumor localization & & & \\
$\quad$ Right & $83(49.1)$ & & \\
$\quad$ Left & $79(46.7)$ & & \\
$\quad$ Bilateral & $7(4.2)$ & & \\
Histology & & & \\
$\quad$ Ductal carcinoma & $143(81.3)$ & & \\
$\quad$ Lobular carcinoma & $19(10.8)$ & & \\
Other & $16(7.9)$ & \\
Surgery & & \\
Radical Mastectomy $101(56.7)$ & \\
Breast-conserving & $77(43.3)$ & \\
Metastasis & & \\
No & $154(88.5)$ & \\
Yes & $20(11.5)$ & \\
\hline
\end{tabular}

Table 2. Comparison of Inflammatory Parameters of Complete Blood Count

\begin{tabular}{lccl}
\hline Parameters & $\begin{array}{c}\text { Patients } \\
\mathrm{n}=178\end{array}$ & $\begin{array}{c}\text { Controls } \\
\mathrm{n}=107\end{array}$ & $\mathrm{p}$ value \\
\hline Leukocyte $^{1}$ & $7.28 \pm 1.99$ & $6.58 \pm 1.5$ & 0.001 \\
Neutrophil $^{1}$ & $4.46 \pm 1.51$ & $3.68 \pm 1.21$ & 0.0001 \\
Lymphocyte $^{1}$ & $2.09 \pm 0.7$ & $2.15 \pm 0.67$ & 0.476 \\
MPV & $8.45 \pm 1.09$ & $8.68 \pm 1.24$ & 0.099 \\
PDW & $13.16 \pm 1.65$ & $16.84 \pm 2.79$ & 0.254 \\
Platelet & $285.81 \pm 71.79$ & $287.26 \pm 75.72$ & 0.871 \\
NLR & $2.37 \pm 1.4$ & $2.0 \pm 1.26$ & 0.0001 \\
PLR & $153.16 \pm 76.21$ & $144.95 \pm 57.19$ & 0.762 \\
MPV/Platelet & $0.317 \pm 0.1$ & $0.325 \pm 0.103$ & 0.436 \\
\hline
\end{tabular}

${ }^{1} \times 10^{3} / \mathrm{mm}^{3}$; MPV, mean platelet volume; NLR, neutrophil lymphocyte ratio; PLR, platelet lymphocyte ratio 
Table 3. Diagnostic Values of the Study Parameters

\begin{tabular}{lccccccc}
\hline & AUC & Cut-off & Sensitivity & Specificity & PPV & NPV & Accuracy \\
\hline Leukocyte & 0.605 & 8.35 & 28.7 & 87.9 & 79.7 & 42.5 & 50.9 \\
Neutrophil & 0.675 & 4.09 & 59 & 70.8 & 77.2 & 50.7 & 63.4 \\
NLR & 0.642 & 2.56 & 30.3 & 84.9 & 77.1 & 42.1 & 50.7 \\
\hline
\end{tabular}

*AUC: Area under curve, PPV: Positive Predictive Value, NPV: Negative Predictive Value, NLR: Neuthrophil Lymphocyte Ratio

Table 4. Univariate and Multivariate Analysis of Risk Factors for the Breast Cancer

\begin{tabular}{|c|c|c|c|c|c|c|c|c|}
\hline \multirow[b]{3}{*}{ Leukocyte } & \multicolumn{4}{|c|}{ Univariate analysis } & \multicolumn{4}{|c|}{ Multivariate analysis } \\
\hline & \multirow{2}{*}{$\frac{\mathrm{OR}}{0.802}$} & \multicolumn{2}{|c|}{$95 \% \mathrm{CI}$} & \multirow{2}{*}{$\frac{\mathrm{p} \text { value }}{0.002}$} & \multirow[t]{2}{*}{ OR } & \multicolumn{2}{|c|}{$95 \%$ CI } & \multirow[t]{2}{*}{$\mathrm{p}$ value } \\
\hline & & $0,696-$ & 0.924 & & & & & \\
\hline Neutrphil & 0.642 & $0,523-$ & 0.787 & 0.0001 & 0.627 & $0.508-$ & 0.774 & 0.0001 \\
\hline Neutrophil/lymphocyte ratio & 0.757 & $0,588-$ & 0.975 & 0.031 & & & & \\
\hline PDW & 1.158 & $1,032-$ & 1.299 & 0.012 & 1.191 & 1.057 & 1.342 & 0.003 \\
\hline
\end{tabular}

*Presence: Patients with breast cancer/Absence: Control group, OR: odds ratio, CI: confidence interval

of the sub-groups was not significant $(\mathrm{p}>0.05)$. There were no significant differences in age, BMI, leukocytes, neutrophils, lymphocytes, platelets, MPV, Hb, Hct, MCV, PDW, NLR, PLR, MPV/Platelet ratio in stage of cancer $(p>0.05)$. There was no significant differences in leukocytes, neutrophils, lymphocytes, Hb, Hct, MCV, MPV, MPV,PDW, NLR, PLR, and MPV/Platelet between patients with metastasis $(n=20)$ and patients without metastasis $(n=158, p>0.05)$. The mean platelet in the group with metastatic $(276.06 \pm 70.94)$ was lower than in non-metastatic $(298.76 \pm 71.32, \mathrm{p}=0.037)$.

Logistic regression analysis showed that elevated neutrophil and (OR: $0.627,95 \% \mathrm{CI}: 0.508-0.774$, $\mathrm{p}=0.001$ ) was an independent variable for predicting breast cancer (Table 4).

\section{Discussion}

As we mention above, in this pilot study we tried to evaluate and compare NLR, PLR and other inflammatory parameters of complete blood count between patients with breast cancer and healthy controls. The average values of leukocyte, neutrophil and NLR were found to be significantly higher in breast cancer patients than healthy group (Table 2). Platelet and PLR values were significantly higher in premenopausal women. There was no significant difference in age and BMI and blood parameters between stages of breast cancer. But platelet count was significantly lower in the metastatic (i.e stage IV) patients. Also there was no significant difference in the mean MPV levels between patients with breast cancer and control groups (Table 2).

It is well known that inflammation has a role in the development and progression of different cancers. Many tumors arise from sites of chronic irritation, infection, and inflammation and also inflammatory cells play important roles in the growth and progression of some tumours (Hussein and Ahmed, 2005; Aliustaoglu et al., 2010; Bae and Kim, 2014; Hoshida et al., 2014; Mitsunaga et al., 2014; Okada, 2014; Sicking et al., 2014). Infiltrates of many immune cells have been detected in malignant tissue (Yildirim et al., 2012). Presence of excess number of neutrophils in tumour stroma has been associated with poor prognosis. Neutrophils induce tumour progression and development of metastases via secretion of cytokines and chemokines and accelerating tumor angiogenesis. It has been detected that NLR estimated from peripheral blood components predicts degree of tumor-promoting inflammation and also prognostic significance of antitumoral immune cell response has been demonstrated. Increased NLR was shown in many tumours. Inflammation is an important process in cancer development and progress (Balkwill and Mantovani, 2001). In one study, leukocyte, neutrophil and NLR were significantly higher in the patient group in accordance with the control group (Thavaramara et al., 2011). In non-malignant diseases contributed to systemic inflammation response, NRL has an independent predictive value of the outcome of such diseases. This increases reliability of NLR for the use as a potential biomarker of the systemic inflammatory response (Chua et al., 2011; Unal et al., 2013; Lee et al., 2014; Yilmaz et al., 2014). In our study patient group has higher leukosyte, neutrophil and NLR than healthy control group (Table 2). Logistic regression analysis showed that high neuthrophil levels are independent predictors of breast cancer risk (Table 3). Highness of the neutrophil level in our cancer patients also supports the previous findings of the presence of inflammatory status in malignant diseases.

The activation of coagulation and fibrinolysis is common among cancer patients. Such tumors have high risk of invasion, metastases, and negative final outcomes(Li et al., 2014b). Previous studies showed that high platelet levels associated with later stage, metastasis and higher risk of recurrence in many types of cancers (Unal et al., 2013; Li et al., 2014a) . Ovarian cancer (Lee et al., 2011), renal cell carcinoma (Cho et al., 2011), colorectal cancer and gastric cancer (Hwang et al., 2012) associated with thrombocytosis had poorer prognosis. In a study on 243.012 patients, Gnerlich J. L. et al. founded higher mortality of breast cancer in younger women than olders (Gnerlich et al., 2009). In our study platelet levels and PLR were higher in premenauposal $(n=78)$ than postmenauposal $(n=100)$ women which may somewhat explain this high mortality rate in younger patients $(\mathrm{p}$ was 0.037 and 0.002 , respectively). In Ufelle et al. study, platelet levels were found to be higher in control group than pre and post-operative breast cancer patients $(\mathrm{p}<0.05$ in both). In our study platelet levels were also higher in 
Yildiz Okuturlar et al

control group but not reached statistical significance.

Our study is retrospective, cross-sectional, singlecenter study with a limited number of patients included. So we could not evaluate the effect of this parameters on prognosis. Another limiting point of this study is that we included only post-surgery but pre-chemotherapy data. So we could not see the effect (if any) of the presence of tumor mass on these blood parameters too. But in Ufelle and his collage's study, there was significant difference between the controls and pre and post-operative blood parameters of breast cancer but no effect of its surgery on these parameters (Ufelle et al., 2012).

In conclusion, our study results show increased inflammatory parameters of complete blood counts in breast cancer patients (in compare to healthy controls). Additionaly high neutrophil levels were an independent predictors of breast cancer risk. Whether these to be used in daily practice need to befurther studied.

\section{Acknowledgements}

The authors wish to thank the study participants for their valuable efforts and time, Ertan Koç for statistical analysis, and Bulent Altundal and Mehmet Hursitoglu for English editing.

\section{References}

Aggarwal BB, Gehlot P (2009). Inflammation and cancer: how friendly is the relationship for cancer patients? Curr Opin Pharmacol, 9, 351-69.

Aliustaoglu M, Bilici A, Ustaalioglu BB, et al (2010). The effect of peripheral blood values on prognosis of patients with locally advanced gastric cancer before treatment. Med Oncol, 27, 1060-5.

Bae SI, Kim YS (2014). Colon cancer screening and surveillance in inflammatory bowel disease. Clin Endosc, 47, 509-15.

Balkwill F, Mantovani A (2001). Inflammation and cancer: back to Virchow? Lancet, 357, 539-45.

Cho DS, Kim SJ, Lee SH, et al (2011). Prognostic significance of preoperative $\mathrm{C}$-reactive protein elevation and thrombocytosis in patients with non-metastatic renal cell carcinoma. Korean J Urol, 52, 104-9.

Chua W, Charles KA, Baracos VE, et al (2011). Neutrophil/ lymphocyte ratio predicts chemotherapy outcomes in patients with advanced colorectal cancer. Br J Cancer, 104, 1288-95.

Edge SB, Compton CC (2010). The American Joint Committee on Cancer: the 7th edition of the AJCC cancer staging manual and the future of TNM. Ann Surg Oncol, 17, 1471-4.

Gasparyan AY, Ayvazyan L, Mikhailidis DP, et al (2011). Mean platelet volume: a link between thrombosis and inflammation? Curr Pharm Des, 17, 47-58.

Gnerlich JL, Deshpande AD, Jeffe DB, et al (2009). Elevated breast cancer mortality in women younger than age 40 years compared with older women is attributed to poorer survival in early-stage disease. J Am College Surg, 208, 341-7.

Hoshida Y, Fuchs BC, Bardeesy N, et al (2014). Pathogenesis and prevention of hepatitis $\mathrm{C}$ virus-induced hepatocellular carcinoma. J Hepatol, 61, 79-90.

Hussein MR, Ahmed RA (2005). Analysis of the mononuclear inflammatory cell infiltrate in the non-tumorigenic, pretumorigenic and tumorigenic keratinocytic hyperproliferative lesions of the skin. Cancer Biol Ther, 4, 819-21.
Hwang SG, Kim KM, Cheong JH, et al (2012). Impact of pretreatment thrombocytosis on blood-borne metastasis and prognosis of gastric cancer. Eur J Surg Oncol, 38, 562-7.

Islam T, Dahlui M, Majid H, et al (2014). Factors associated with return to work of breast cancer survivors: a systematic review. BMC Public Health, 14, 8.

Lee M, Kim SW, Nam EJ, et al (2011). The impact of pretreatment thrombocytosis and persistent thrombocytosis after adjuvant chemotherapy in patients with advanced epithelial ovarian cancer. Gynecol Oncol, 122, 238-41.

Lee SK, Lee SC, Park JW, et al (2014). The utility of the preoperative neutrophil-to-lymphocyte ratio in predicting severe cholecystitis: a retrospective cohort study. $B M C$ Surg, 14, 100.

Li F-X, Wei L-J, Zhang H, et al (2014a). Significance of Thrombocytosis in Clinicopathologic Characteristics and Prognosis of Gastric Cancer. Asian Pac J Cancer Prev, 15, 6511-7.

Li Y, Wei S, Wang J, et al (2014b). Analysis of the factors associated with abnormal coagulation and prognosisin patients with non-small cell lung cancer. Zhongguo Fei Ai Za Zhi, 17, 789-96 (in Chinese).

Majeed W, Aslam B, Javed I, et al (2014). Breast cancer: major risk factors and recent developments in treatment. Asian Pac J Cancer Prev, 15, 3353-8.

Mitsunaga A, Tagata T, Hamano T, et al (2014). Metachronous early gastric cancer over a period of 13 years after eradication of Helicobacter pylori. Clin J Gastroenterol, 7, 490-5.

Okada F (2014). Inflammation-related carcinogenesis: current findings in epidemiological trends, causes and mechanisms. Yonago Acta Med, 57, 65-72.

Pierce BL, Ballard-Barbash R, Bernstein L, et al (2009). Elevated biomarkers of inflammation are associated with reduced survival among breast cancer patients. J Clin Oncol, 27, 3437-44.

Sicking I, Edlund K, Wesbuer E, et al (2014). Prognostic influence of pre-operative $\mathrm{C}$-reactive protein in nodenegative breast cancer patients. PLoS One, 9, 111306.

Siegel R, Naishadham D, Jemal A (2012). Cancer statistics for Hispanics/Latinos, 2012. CA Cancer J Clin, 62, 283-98.

Teramukai S, Kitano T, Kishida Y, et al (2009). Pretreatment neutrophil count as an independent prognostic factor in advanced non-small-cell lung cancer: an analysis of Japan Multinational Trial Organisation LC00-03. Eur J Cancer, 45, 1950-8.

Thavaramara T, Phaloprakarn C, Tangjitgamol S, et al (2011). Role of neutrophil to lymphocyte ratio as a prognostic indicator for epithelial ovarian cancer. J Med Assoc Thai, 94, 871-7.

Ufelle SA, Ukaejiofo EO, Neboh EE, et al (2012). Some haematological parameters in pre- and post-surgery breast cancer patients in enugu, nigeria. Int J Current Biological Medical Sci, 2, 188-90.

Unal D, Eroglu C, Kurtul N, et al (2013). Are neutrophil/ lymphocyte and platelet/lymphocyte rates in patients with non-small cell lung cancer associated with treatment response and prognosis? Asian Pac J Cancer Prev, 14, 5237-42.

Yildirim M, Suren D, Goktas S, et al (2012). The predictive role of Bcl-2 expression in operable locally advanced or metastatic gastric carcinoma. J BUON, 17, 106-9.

Yilmaz H, Ucan B, Sayki M, et al (2014). Usefulness of the neutrophil-to-lymphocyte ratio to prediction of type 2 diabetes mellitus in morbid obesity. Diabetes Metab Syndr, (in Press). 